\title{
Exploring volatility of carbon price in European Union due to COVID-19 pandemic
}

\author{
Feng Dong ${ }^{1}\left[\right.$ ] $\cdot$ Yujin Gao $^{1} \cdot{\text { Yangfan } \mathrm{Li}^{1} \cdot \text { Jiao } \mathrm{Zhu}^{1} \cdot \text { Mengyue Hu}^{1} \cdot \text { Xiaoyun Zhang }}{ }^{1}$
}

Received: 2 July 2021 / Accepted: 16 August 2021 / Published online: 5 September 2021

(C) The Author(s), under exclusive licence to Springer-Verlag GmbH Germany, part of Springer Nature 2021

\begin{abstract}
The European Union (EU) Emissions Trading System is the most important means for the EU to achieve carbon neutrality, but it has been severely affected by the outbreak of COVID-19 in Europe, and carbon price have fluctuated sharply. Research on the driving factors of carbon price during this period will help maintain the stability of the carbon emissions trading market and promote the realization of carbon neutrality. This study selected the EU carbon allowance futures price as the research object and applied the Bai-Perron structural break test to analyze the factors that influences carbon price fluctuations using the Johansen cointegration technique and the Newey-West regression estimation. Studies have shown that the outbreak of COVID-19 and the " $€ 750$ billion green recovery plan" both had a significant impact on EU carbon price. Carbon price has also undergone significant structural changes. Under the influence of these two factors, the relationship between the level of economic development and carbon price displayed a short-term negative correlation. At the same time, oil price and interbank dismantling rates were also important factors affecting carbon price, while the impact of the clean development mechanism on carbon price was not significant. The study confirmed the effectiveness of the EU's "green recovery plan" in stabilizing the carbon market during the COVID-19 pandemic and will provide a reference for the formulation of economic recovery policies of countries around the world.
\end{abstract}

Keywords Carbon price $\cdot$ Carbon neutrality $\cdot$ COVID-19 $\cdot$ Green recovery plan

\section{Introduction}

Global warming is one of the world's major challenges and has become a major threat to the sustainable development of mankind (Liu and Dong 2021). To mitigate climate change, more than 70 countries have made international climate commitments in accordance with the Paris Agreement, stating that they will achieve net zero carbon dioxide emissions by 2050 and limit the temperature rise to less than $2{ }^{\circ} \mathrm{C}$. The European Union (EU)'s Green New Deal also promises to achieve carbon neutrality by 2050 . As the most important means of reducing carbon emissions, the EU Emissions Trading System

Responsible Editor: Nicholas Apergis

Feng Dong

dongfeng2008@126.com

Xiaoyun Zhang

ts18070012A31@cumt.edu.cn

1 School of Economics and Management, China University of Mining and Technology, Xuzhou 221116, People's Republic of China
(EU ETS) will play the core driving role in achieving the international climate commitments.

The EU ETS plays an important role in enabling the EU to mitigate the global warming caused by carbon dioxide emissions (Aune and Golombek 2021). It establishes carbon emission quotas to strictly control the carbon dioxide emissions of restricted sectors and makes full use of market mechanisms for carbon emission rights trading to coordinate and resolve the conflict between environmental issues and low-carbon economic development. The sectors covered by the EU ETS include the power sector, manufacturing, and domestic flights within the EU Economic Area. Restricted departments can obtain emission units by auctioning carbon allowances and choose to use the auctioned allowances for their own offset or trade. Due to the differences in the emission reduction costs and emission reduction technologies of various companies in the market, the demand for carbon emission rights differs. Companies with excellent emission reduction capabilities can sell their additional carbon allowances to obtain profits, while companies with inferior emission reductions can purchase carbon allowances in the carbon market to reduce their production costs. In this way, the EU ETS can achieve double 
emission reduction benefits through carbon pricing. Therefore, the carbon price plays a vital role in the operation of the EU ETS. The carbon price not only reflects the government's efforts to reduce carbon emissions, but also is related to the effectiveness of the carbon emissions trading market (Liu et al. 2021).

As the EU ETS entered its third stage, carbon price gradually increased and remained stable through a series of quota reforms. In the early phase of the third stage of the EU ETS, there was an oversupply of carbon allowances, and therefore, carbon price was maintained at a low level. To ensure that the carbon price can be used effectively as a signal and to solve the oversupply of allowances, the European Commission has promulgated a series of supply-side reform measures (Martin 2020). First, the government has implemented a linear decrease in the total quota. At the beginning of the third stage, the European Commission determined the total number of allowances and formulated an allocation plan for the carbon allowances in each member state. On the basis of the initial allocation, the total quota was reduced by $1.74 \%$ per year. Therefore, the goal of reducing the total quota at the end of the third phase by $21 \%$ compared with the total quota at the beginning of the first phase has been achieved. Second, a discounted auction policy was implemented. By postponing the auction of quotas from 2014 to 2016, the problem of quotas supply surplus was resolved in the short term. The postponed quotas were auctioned from 2019 to 2020, and therefore, the total amount of auction quotas was not changed. During this period, this part of the quotas entered the market reserve mechanism. At the same time, the European Commission also implemented a market stabilization reserve mechanism. When the number of quotas circulating in the market is too large, the European Commission incorporates part of the future auction quotas into the market reserve. In contrast, if the number of circulating quotas is too small, the market reserve mechanism will release carbon allowances (Richstein et al. 2015). With the promulgation of various supply-side policies, especially the operation of the market stability reserve mechanism, the supply flexibility of carbon allowances has been significantly improved and the problem of oversupply has been alleviated. As a result, the carbon price has risen sharply as shown in Fig. 1 and has gradually stabilized at around $€ 25 /$ ton.

However, with the outbreak of the COVID-19 pandemic, most parts of the world have been under prolonged lockdowns, and social demand has dropped sharply, which has generated great instability in the carbon market. During the initial large outbreak in Italy, EU carbon price fell sharply in a short time, from $€ 25$ to $€ 15 /$ ton, which was significantly lower than the previous year's $€ 25 /$ ton. Later, under the influence of the market reserve mechanism, the carbon price rebounded briefly (Gerlagh et al. 2020). Due to the overall sluggish economic situation in the EU, the public's demand for economic recovery has intensified. In response, the European Commission finally passed the " $€ 750$ billion green recovery plan," which has stabilized the carbon market. The carbon price has risen significantly, gradually rising from $€ 20$ to $€ 27 /$ ton, and has remained stable. The trend of carbon futures price indicates that during the COVID-19 pandemic, carbon price fluctuated sharply and was extremely unstable. Therefore, this study focused on carbon price during the COVID-19 pandemic.

The rest of this article is arranged as follows. Section "Literature review" summarizes the previous literature on carbon price driving factors. Section "Methods and data" briefly introduces the research methods used to analyze the carbon price and the selected relevant data. Section "Results and discussion" presents and discusses the empirical results. Section "Conclusions and policy recommendations" presents conclusions and policy recommendations.

\section{Literature review}

A reasonable carbon price is an important condition for the emissions trading system to play a role in reducing emissions (Duan et al. 2021). An effective carbon price can not only encourage companies to improve their emission reduction efficiency, but also creates fiscal revenue enabling the government to make green investments (Feng et al. 2011). Studies have shown that if carbon price will remain low for a long time, it will weaken the confidence of market participants, thereby affecting the efficiency of emission reductions (Liu et al. 2021). In contrast, a reasonably high level of carbon price will promote the development of innovative green technologies and improve emission reduction efficiency (Li et al. 2021). De Perthuis and Trotignon (2014) believed that both short-term social emission capacity and long-term environmental investment behavior will be affected by the operating efficiency of an emissions trading system, and that carbon price is the most important factor influencing the operating efficiency of an emissions trading system. Therefore carbon price is the core driving factor in the operation of an emissions trading system. If its fluctuations are too severe, they will directly affect the realization of the EU's emission reduction targets, which will not be conducive to the sustainable development of society (Markus et al. 2021). Therefore, many studies have been conducted to determine the driving factors of carbon price.

The price of carbon emission rights embodies the relative relationship between carbon allowance supply and demand (Zhao et al. 2021). Because carbon allowances are a special policy commodity, the supply of allowances is determined by government policies (Hao et al. 2021). Therefore, some researchers have studied carbon price from this perspective. These studies have found that when a carbon emission market 


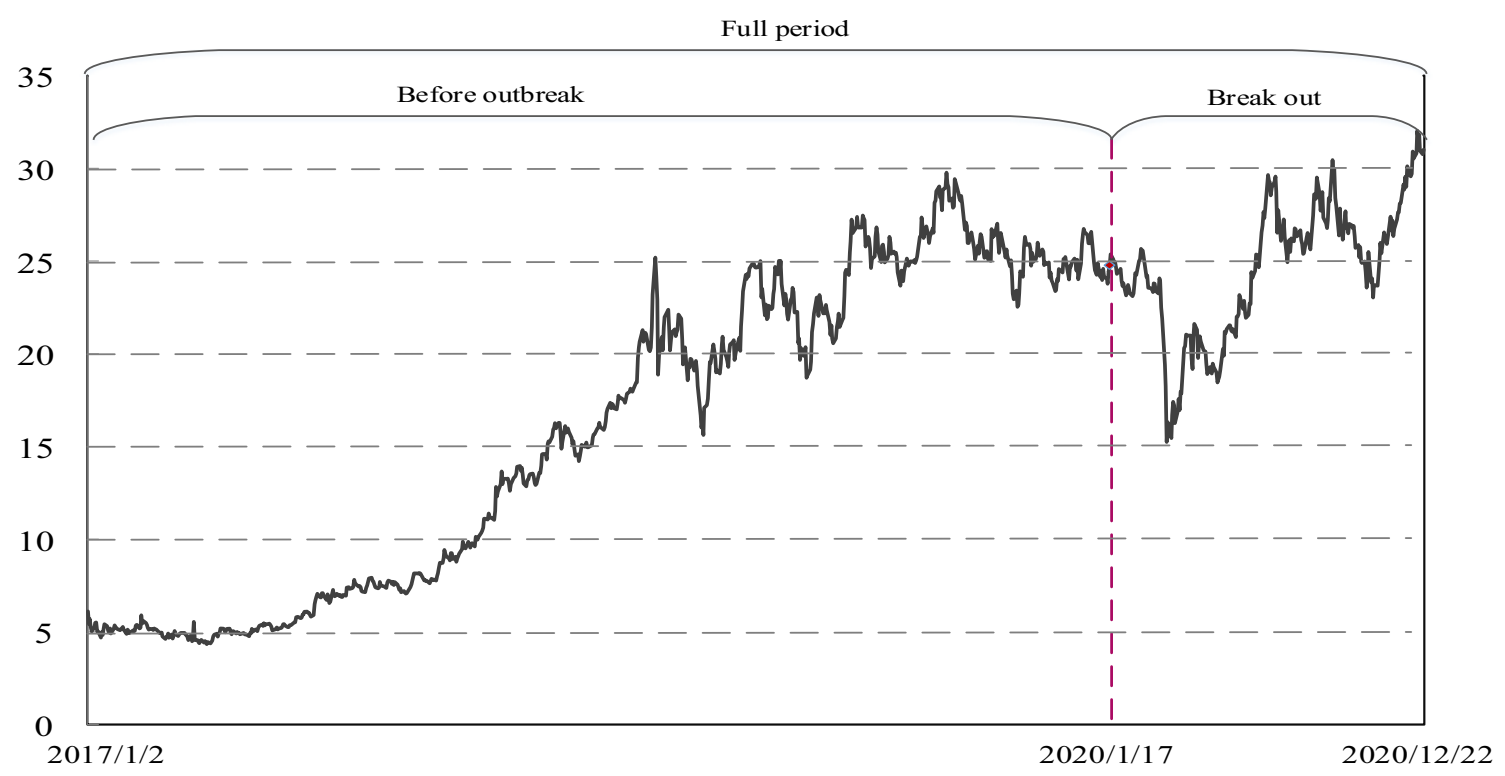

Fig. 1 Carbon price trend

is established, if the government sets a total number of carbon allowances that is too high, companies will obtain too many carbon allowances (Zhou and Chen 2021). The subsequent implementation of a free allocation policy will cause the market to see that the supply of allowances is far greater than the demand (Alberola et al. 2008). Due to the lack of profit-driven approach, there is little incentive for companies to cut their own emissions, and carbon price remains depressed (Mansanet-Bataller et al. 2011). Additionally, the government's major announcements on the carbon market will also have a significant impact on carbon price. Koch used the event research method to study the reaction of carbon price to the government's adjustment of total carbon emissions. The results proved that the carbon market is very sensitive to related political events (Koch et al. 2016).

In the quantitative analysis of carbon price, researchers have found that energy price, macroeconomic development, major social events, and other factors will affect the demand for carbon allowances, which will cause fluctuations in carbon price (Adhurim and Mario 2021; Ji et al. 2018). MansanetBataller et al. (2007) were the first researchers to use multiple linear regression methods to study the impact of energy price and electricity price on carbon price. Research has shown that energy price is the most important factor affecting carbon price trends (Mansanet-Bataller et al. 2007). When studying the impact of the macroeconomic situation on carbon price, Bel and Joseph (2015) found that there were large fluctuations in carbon price in the first and second stages of the EU ETS. In a research based on carbon emission data, they found that both carbon price and the degree of emission reduction will be affected by the economic crisis (Bel and Joseph 2015). With the continuous development of the carbon market, financial elements have been introduced. The carbon finance market currently contains a large number of innovative carbon allowance financial derivatives, such as carbon futures, carbon options, and carbon forwards. With the introduction of financial elements, the impact of financial investment and speculation on the carbon market cannot be ignored (Rittler 2012).

There have been many studies of the driving factors of EU ETS carbon price, but most have focused on only one or several factors, such as the economic situation, energy price, and quota reforms, with little attention given to the impact of major social events on carbon price. In particular, there has been no research conducted regarding the mechanism of how the COVID-19 pandemic has affected carbon price. Therefore, this study used the Bai-Perron (B-P) structural break test to examine the structural changes in carbon price during the pandemic, and through the introduction of dummy variables, a comprehensive analysis of the mechanism of carbon price drivers during the COVID-19 pandemic was conducted. The study found that the outbreak of COVID-19 and the proposal of the green recovery plan have changed individual's investment intentions, resulting in a negative correlation between carbon price and the macroeconomic situation in the short term. When studying the impact of multiple factors on carbon price, many studies have directly used an ordinary least squares (OLS) method to perform a multiple linear regression, which has resulted in the research results often having autocorrelation and heteroscedasticity problems. These research results are unreliable, which makes it impossible to effectively study carbon price fluctuations. The Newey-West estimation method adopted in this study effectively overcomes the problems of heteroscedasticity and autocorrelation.

This study made several contributions to carbon price research. First, a quantitative analysis of the impact of the COVID-19 pandemic on the price of carbon allowances was 
conducted, and a detailed description of the mechanism of the impact of other variables on carbon price during the COVID-19 pandemic was obtained. Second, by adopting the B-P structural break test and introducing dummy variables based on the results, the subjectivity of introducing dummy variables was avoided, and the effectiveness of the EU's green recovery plan was affirmed.

\section{Methods and data}

\section{Method}

\section{The B-P structure breakpoint test}

There are many methods for structural breakpoint test, such as the Chow test, residual test based on recursive least squares, and Quandt-Andrews test. Compared with other structural breakpoint test methods, the B-P structural breakpoint test can not only determine the number of breakpoints in the time series, but also locate the time points when the breakpoints occur, leading to the effective capture of structural mutation points. Therefore, the B-P multi-breakpoint detection algorithm was applied to detect structural changes in the carbon market price. The corresponding test model was as follows:

$y_{t}=x_{1 t}^{\prime} \beta+x_{2 t}^{\prime} \delta_{1}+\varepsilon_{t}, t=1,2, \ldots, T_{1}$

$y_{t}=x_{1 t}^{\prime} \beta+x_{2 t}^{\prime} \delta_{2}+\varepsilon_{t}, t=T_{1}+1, T_{1}+2 \ldots T_{2}$

$y_{t}=x_{1 t}^{\prime} \beta+x_{2 t}^{\prime} \delta_{n+1}+\varepsilon_{t}, t=T_{n}+1, T_{n}+2 \ldots T$

where $y_{t}$ is the dependent variable valued at time $t, x_{1 t}$ and $x_{2 t}$ are the covariate vectors, $\beta$ and $\delta_{j}(j=1,2, \cdots n)$ are the coefficients of the corresponding covariate vectors, $\varepsilon_{t}$ is the random error term, and $T_{1}, T_{2}, \cdots T_{n}$ are the positions where structural breakpoints occur. This method mainly uses a large sample theory to construct statistics related to the detection of structural breakpoints. For example, the $\operatorname{Supft}(k)$ statistic is used to detect whether a time series has structural mutations, and the $\operatorname{SupFt}(i / 1+i)$ statistic is used to detect how many structural mutations have occurred. The Bayesian information criterion is used to determine the optimal number of breakpoints and the breakpoint occurrence time (Bai and Perron 2003).

\section{The Newey-West regression model}

The generalized linear regression model is

$$
\begin{aligned}
& y=x \beta+\varepsilon \\
& E[\varepsilon \mid x]=0 \\
& E\left[\varepsilon \varepsilon^{\prime} \mid x\right]=\sigma^{2} \Omega
\end{aligned}
$$

where $y$ represents the $(T \times 1)$ order column vector, $x$ is the $(T \times K)$ order matrix ( $K$ represents the number of regression variables), $\epsilon$ represents the $(T \times 1)$ order residual vector, and $\sigma^{2} \Omega$ is the $(T \times T)$ order covariance matrix of the residuals. Through a linear regression analysis, the regression coefficient $\beta$ was obtained and the significance of the regression result was determined.

In the classical hypothesis of the OLS method, the explanatory variable $x$ is the predetermined variable. For different values of $\varepsilon_{i}$, it obeys the basic assumption of mutual independence and homoscedasticity, and therefore, the matrix $\Omega$ is the identity matrix. Suppose that the estimate of $\beta$ is $\widehat{\beta}$

$\beta^{*}=\left(x^{\prime} x\right)^{-1} x^{\prime} y$

By further deriving $\widehat{\beta}$, the covariance matrix can be obtained as

Var $=\frac{1}{T}\left(\frac{1}{T} x^{\prime} x\right)^{-1}\left(\frac{1}{T} x^{\prime}\left[\sigma^{2} \Omega\right] x\right)\left(\frac{1}{T} x^{\prime} x\right)^{-1}$

However, the generalized linear regression model no longer follows the basic assumption of an independent and identical distribution, and there may be heteroscedasticity and autocorrelation problems for the different $\varepsilon_{i}$ and $\varepsilon_{j}$ values, which will cause the covariance statistics of $\widehat{\beta}$ to change. Assume that $Q$ is the intermediate matrix of the covariance matrix

$$
\begin{aligned}
Q & =\frac{1}{T} x^{\prime}\left[\sigma^{2} \Omega\right] x \\
& =\frac{1}{T} \sum_{i=1}^{T} \sum_{j=1}^{T} \sigma_{i j} x_{i} x_{j}^{\prime}
\end{aligned}
$$

If the residual $\varepsilon$ has heteroscedasticity and autocorrelation problems, the Newey-West estimate corrects the heteroscedasticity and autocorrelation problems, so that a consistent estimate of $Q$ is recorded as $M$

$M=\frac{1}{T}\left\{\sum_{t=1}^{T} e_{t}^{2} x_{t} x_{t}^{\prime}+\sum_{l=1}^{L} \sum_{t=l+1}^{T} w_{l} e_{t} e_{t-l}\left(x_{t} x_{t-l}^{\prime}+x_{t-l} x_{t}^{\prime}\right)\right\}$

Among them

$w_{l}=1-\frac{l}{1+L}$

where $L$ represents the maximum lag order affected by the residual lag term, and $w_{l}$ is the coefficient of the lag period $l$. And the longer the lag period, the smaller the coefficient of $w_{l}$. The first term in the brackets above is the correction for heteroscedasticity, and the second term is the correction for autocorrelation. The Newey-West estimation can avoid the autocorrelation and heteroscedasticity problems of the 
residual items through the abovementioned correction of the estimator, and can obtain the consistent estimator of $Q$, making the $\beta$ statistical test effective (Newey and West 1994).

\section{Data}

\section{The dependent variable}

The dependent variable selected in this study was the EU carbon allowance futures price (EUA). In EU carbon market transactions, futures transactions account for a larger share than spot transactions, and the futures market has a price discovery function. When the COVID-19 pandemic began, the carbon market became extremely unstable, with clear price fluctuations. The sensitivity of futures price to market changes can reflect the supply and demand relationship of carbon allowances more effectively than spot price, and it can also effectively predict the trends in carbon price (Mansanet-Bataller et al. 2011).

\section{Explanatory variables}

This study analyzed the impact of the COVID-19 pandemic and the EU's green recovery plan on carbon price. Through the structural breakpoint test results, it was found that during the outbreak of COVID-19 in the EU, carbon price has undergone significant structural changes. At the same time, with the introduction of the green recovery plan, carbon price has also undergone structural changes. Therefore, based on the structural breakpoint test results, dummy variables were introduced to characterize the impact of the COVID-19 pandemic and the EU's green recovery plan on the carbon market. A value of 0 was taken before March 13, 2020, after which a value of 1 was taken and recorded as COVID to describe the impact of the COVID-19 pandemic (COVID) on carbon price. A value of 0 was taken before June 18,2020, after which a value of 1 was taken and recorded as RP to describe the impact of the green recovery plan (RP) on carbon price.

\section{Control variables}

Control variables are mainly used to separate the impact of other factors on carbon price. As a special policy commodity, the price of carbon emission rights is affected in many ways. By evaluating the relevant literature (Creti et al. 2012; Aatola et al. 2013; Zhu et al. 2019; Duan et al. 2021), factors influencing carbon price were found to include the following:

1. The level of economic development: Traditional economic theory indicates that rapid economic development will drive an increase in industrial production, and the prosperity resulting from the enhanced industrial production will lead to large carbon dioxide emissions, increasing the demand for carbon allowances. To express the impact of the level of economic development on the carbon price, the EU economic prosperity index (EC) was used to represent the level of economic development.

2. Energy price: Carbon dioxide is mainly emitted from the use of primary energy. Although significant efforts are being made to develop clean energy, technical defects and the instability of clean energy have prevented its wide-scale promotion. Fossil fuel energy is still the main source of energy generation worldwide (Pan and Dong 2021). Therefore, changes in the price of fossil fuel energy affect the trend of carbon price. To express the impact of fossil fuel energy price on carbon price, Brent crude oil futures price $(\mathrm{Br})$ was selected as the control variable.

3. Financial environment: With the international community actively advancing the process of carbon emission reduction, the carbon financial market is developing rapidly. This will not only promote the improvement of emission reduction technologies on a global scale and accelerate the development and utilization of new energy, but this will also have a valuable discovery function. The financial nature of carbon emission rights means that changes in the financial environment will affect carbon price trends. To express the impact of the financial environment on the carbon price, the EU's interpeer dismantling interest rate (I) was used as the control variable.

4. Clean development mechanism (CDM): As an important market for carbon credits, the CDM provides flexibility for countries to implement carbon emission reduction. Carbon emission reduction is the responsibility of every country, but the accumulated carbon dioxide emissions of developing and developed countries are different. To ensure fairness, the Kyoto Protocol introduced a CDM with flexible performance characteristics. The CDM is mainly used by developing countries to sell certified emission reductions to enterprises in developed countries that lack carbon emission rights through the secondary market. Developing countries can obtain financial support for technology upgrading, and developed countries can use it to offset carbon dioxide emissions. To express the impact of the project on carbon price, the certified emission reduction price (Cer) was selected to measure this influencing factor.

Each variable was sorted, as shown in Table 1.

The descriptive statistics for each variable are given in Table 2. Due to the negative value of the peer dismantling interest rate, only some variables were processed as logarithms. The sample interval of all variables was from January 17, 2020, to November 30, 2020, excluding all holidays, providing a total of 225 observations. 
Table 1 Variable

\begin{tabular}{lll}
\hline Variable & Representative meaning & Data sources \\
\hline EUA & EU carbon allowance futures price & Wind database \\
Ec & The EU economic prosperity index & Wind database \\
$\mathrm{Br}$ & Brent crude oil futures price & Wind database \\
$\mathrm{I}$ & The EU's interpeer dismantling interest rate & Wind database \\
Cer & The certified emission reduction price & Wind database \\
COVID & The impact of the COVID-19 pandemic & \\
RP & The impact of the green recovery plan & \\
\hline
\end{tabular}

\section{Results and discussion}

\section{Stationarity analysis}

\section{Unit root test}

Because the data used in this study were time series data, it was necessary to perform a unit root test before performing a regression analysis. There are many methods of unit root test, such as the Dickey-Fuller (DF), augmented DF (ADF), Phillips-Perron, and Kwiatkowski-Phillips-Schmidt-Shin tests. The widely used ADF unit root test was selected for use in this study. Because dummy variables will not affect the cointegration relationship, only the unit roots of non-dummy variables were tested. The results are shown in Table 3.

The unit root test revealed that these variables were all non-stationary time series, but they were all stable after a first-order difference equation was solved. Therefore, these variables could be tested for cointegration. If the cointegration test would not be performed on these variables before the regression, the result would likely be a pseudo-regression, and the regression result would also lose its meaning.

\section{The Johansen cointegration test}

To use the vector error correction model (VECM) to further verify the long-term cointegration relationship between

Table 2 Descriptive statistics

\begin{tabular}{lllllll}
\hline Variable & Nobs & Mean & Max & Min & Standard error & VIF \\
\hline LnEUA & 225 & 3.17 & 3.42 & 2.72 & 0.15 & - \\
LnEc & 225 & 4.43 & 4.64 & 4.16 & 0.15 & 3.08 \\
LnBr & 225 & 3.70 & 4.18 & 2.96 & 0.24 & 4.19 \\
I & 225 & -0.46 & -0.44 & -0.49 & 0.01 & 4.30 \\
LnCer & 225 & -1.26 & -1.11 & -1.43 & 0.07 & 3.18 \\
COVID & 225 & 0.82 & 1.00 & 0.00 & 0.38 & 6.11 \\
RP & 225 & 0.52 & 1.00 & 0.00 & 0.50 & 6.16 \\
\hline
\end{tabular}

variables, we first had to determine the optimal lag order of the variables according to the vector autoregressive model. The Johansen maximum likelihood estimation method was then used to test whether there was a cointegration relationship between the variables. The test results are shown in Tables 4 and 5. According to the likelihood ratio, the Akaike information criterion, and final prediction error criteria in Table 4, it was determined that the lag 3 order was better than the lag 1 order. Therefore, the optimal lag order of the VECM was the lag 3 order.

The Johansen cointegration test results showed that in the null hypothesis, there was no cointegration relationship as shown in Table 5. The trace statistic was 90.69, which was much larger than the critical value of 69.82 at the $5 \%$ significance level, and therefore, the null hypothesis that there was no cointegration relationship was rejected. Under the assumption that there were two cointegration relationships, it was rejected at the $10 \%$ significance level, and the null hypothesis was not rejected at the $5 \%$ significance level. There were two cointegration relationships, and therefore, there was a longterm stable equilibrium relationship between the variables.

\section{Discussion of the structural mutation test results}

The results of the B-P structural breakpoint test of EU carbon price during the COVID-19 pandemic are shown in Table 6 . After comparing the scaled $F$ statistic with the critical value, it was found that there were three structural mutation points. The scaled $F$ statistic was significantly smaller than the critical value. The original hypothesis was rejected, and there were not three structural mutation points. When it was assumed that there were two structural mutation points, the planned $F$ value was greater than the critical value; that is, the null hypothesis was not rejected. Therefore, the carbon futures price had two sudden changes in this sample interval.

The specific location of the carbon price breakpoint is shown in Fig. 2. The EU carbon price structure breakpoint diagram shows that the carbon price experienced structural mutations on March 13, 2020, and June 18, 2020. The first structural break was mainly due to the fact that various parts of Europe were experiencing an outbreak of COVID-19 at this time. The large extent of the COVID-19 pandemic caused national governments to initiate lockdown measures, and many large-scale activities were prohibited. Factories were required to cease operations unless their operational processes were controlled by machines, schools conducted online teaching, and many transportation facilities were also suspended due to health policies. Governments began to realize the severity of the situation as the crisis unfolded (Khurshid and Khan 2020). At the same time, many key climate conferences were postponed. With the postponement of the climate conference and the reduction of economic activity, such as industrial production and ground transportation, the overall 
Table 3 Unit root test

\begin{tabular}{lllll}
\hline Variable & Original sequence ADF & $P$ value & First-order difference ADF & $P$ value \\
\hline LnEUA & -2.39 & 0.39 & -15.96 & 0.00 \\
LnEc & -1.78 & 0.71 & -14.90 & 0.00 \\
LnBr & -2.13 & 0.52 & -12.97 & 0.00 \\
I & -1.36 & 0.60 & -15.36 & 0.00 \\
LnCer & -2.54 & 0.31 & -13.33 & 0.00 \\
\hline
\end{tabular}

economic operation of European society became uncertain. The carbon futures market was not active, which led to a pessimistic attitude by the public towards carbon futures investment expectations. The carbon price began to fall.

The carbon price displayed a clear upward trend after the second structural mutation point occurred. This was because at the end of May, the European Commission proposed the $€ 750$ billion green recovery plan in response to the impact of the COVID-19 pandemic, with one-third of the funds used for a transformation to a green economy in member states, accelerating the process of achieving "carbon neutrality." The recovery plan had several effects. First, part of the funds was used to strengthen the EU's ability to respond to public safety and health crises, form a health and safety protection system, and improve the handling efficiency in response to health emergencies. Second, the focus of the plan was to provide financial support for a green economic recovery among the member states, with a focus on the transformation and upgrading of member states. Funds were allocated to serve the climate commitments of the Paris Agreement and the realization of carbon neutrality. In addition, the EU's Green Recovery Plan also actively guided private investment and gave full play to the driving role of private investment in economic recovery. At the same time, it was envisaged to increase investment in public projects and promote employment. Some of the funds were used to provide youth employment and the improvement of public infrastructure, thereby increasing social demand. As an important part of the "European Green Agreement," the green recovery plan significantly stabilized the carbon futures market.

The European Green Agreement is the core of the EU's economic recovery response to the COVID-19 crisis. It aims

Table 4 Determination of the optimal lag order

\begin{tabular}{lllllll}
\hline Lag & LL & LR & FPE & AIC & SC & HQ \\
\hline 1 & 2813.27 & 3255.44 & $8.29 \mathrm{e}-18$ & -25.14 & $-24.60^{*}$ & $-24.93^{*}$ \\
2 & 2848.04 & 65.76 & $7.59 \mathrm{e}-18$ & -25.23 & -24.31 & -24.86 \\
3 & 2879.35 & $57.81^{*}$ & $7.17 \mathrm{e}^{-18 *}$ & $-25.29^{*}$ & -23.98 & -24.76 \\
4 & 2899.11 & 35.59 & $7.54 \mathrm{e}^{-18}$ & -25.24 & -24.55 & -24.56 \\
\hline
\end{tabular}

*More significant than other results to achieve carbon neutrality by 2050 and vigorously promote the EU's green transformation. Therefore, during the COVID-19 pandemic, the European Commission developed a "green economy" as the focus of its recovery plan and achieved environmental goals, while ensuring economic recovery and stimulating economic growth. To achieve the goal of carbon neutrality, in June 2020, the European Central Bank will add a further $€ 600$ billion to the $€ 750$ billion green recovery plan. After a series of green recovery stimulus measures, the public is beginning to be optimistic about the prospects of the carbon futures market and their willingness to invest has increased. As a result, the carbon price has undergone a structural mutation and has gradually risen.

\section{Discussion of the Newey-West regression results}

According to the Newey-West regression results in Table 7, it can be seen that the adjusted $R^{2}$ value is 0.86 and the $F$ value is 230 , which indicates that the model has a high degree of goodness of fit and has passed the significance test.

The results of the Newey-West regression showed that both the impact of the COVID-19 pandemic and the recovery plan have had a significant impact on carbon price. Moreover, the results showed that carbon price and the impact of the COVID-19 pandemic were negatively correlated, while there was a positive correlation with the recovery plan. There were two aspects to the impact of the COVID-19 pandemic on carbon price. On the one hand, as the pandemic intensified, countries adopted lockdown and quarantine measures to prevent the spread of the virus. Social and economic activities decreased, the overall social demand decreased, and industrial

Table 5 Cointegration test

\begin{tabular}{lllll}
\hline HY & EG & Trace & Critical value & $P$ \\
\hline None* & 0.16 & 90.45 & 69.82 & 0.00 \\
At most 1* & 0.09 & 50.03 & 47.86 & 0.03 \\
At most 2 & 0.07 & 28.03 & 29.80 & 0.07 \\
At most 3 & 0.04 & 11.09 & 15.49 & 0.21 \\
At most 4 & 0.01 & 1.43 & 3.84 & 0.23 \\
\hline
\end{tabular}

*Significant level at 5\% 
Table 6 The scaled $F$ statistic critical values

\begin{tabular}{llll}
\hline Break test & $F$ statistic & Scaled $F$ statistic & Critical value \\
\hline 0vs1* & 10.21 & 10.21 & 8.58 \\
1vs2* & 10.16 & 10.16 & 10.13 \\
2vs3 & 1.27 & 1.27 & 11.14 \\
\hline
\end{tabular}

*More significant than other results

production stagnated. Thus, the COVID-19 pandemic affected carbon price from the demand side of carbon emission rights. On the other hand, as the pandemic continued to spread, many key climate conferences were postponed, including the $26^{\text {th }}$ Conference of the Parties (COP26), with the consequence that discussions and decisions on the operating rules of the international carbon market were suspended. Therefore, the future of the carbon market is uncertain. This has affected investor actions and led to a drop-in carbon price. Because the market cannot produce a vaccine that can effectively control the COVID-19 pandemic, the length of the impact of the COVID-19 pandemic on the carbon market cannot be determined, which will further aggravate the uncertainty of the carbon market.

Due to the ongoing lockdowns in many countries, the economic situation has continued to deteriorate, and the public's desire for recovery has become more urgent. Some studies have shown that although the pandemic has had an adverse impact on the economy, it has also presented an opportunity to accelerate the development of a low-carbon economy and sustainable development. In this international context, the EU's $€ 750$ billion green recovery plan was introduced. As an important part of the EU's green agreement, the plan is critical for stabilizing the EU carbon market. The measures included are largely designed to help member states achieve economic recovery. However, all budget expenditures must be in line with the Paris Agreement to reduce greenhouse gases and achieve the 2050 "carbon neutral" target. In total, about onethird of the funds are dedicated to climate change, support the green transformation, and accelerate the carbon neutral transition. This has strengthened the public's confidence in the green recovery, and investors are also optimistic about the future expectations of the carbon market. As a result, carbon price has steadily recovered during the pandemic, reaching a peak of $€ 30 /$ ton. Although the recovery plan has had a positive role on carbon price, as the COVID-19 pandemic has worsened, carbon price has remained uncertain, and continuous attention is needed to avoid extreme fluctuations in the carbon market.

From the regression results of the control variables, it was found that the economic prosperity index, crude oil price, and peer dismantling interest rates all had a significant impact on carbon price. The research shows that carbon price and economic prosperity index were negatively correlated. This is different from previous conclusions. According to traditional theory, it is believed that the development of the macroeconomy will drive energy consumption, thereby increasing the demand for carbon emission rights, leading to an increase in carbon price (Alberola et al. 2008; Ji et al. 2018). But due to the public health issues around the COVID-19 pandemic, people have become more aware of the importance of environmental protection. The public's awareness of environmental protection has gradually increased, and people are paying more attention to green projects (Hua et al. 2021). As the EU government implements the economic recovery plan, it will actively guide the public's expectations for the development of the green economy, resulting in a change in the public's investment intentions. The public is more willing to invest in projects related to green development. As a result, despite the reduction in economic activity in the EU, the demand for carbon emission rights has increased, leading to an increase in the price of carbon futures. At the same time, the public is also aware that rapid economic development may aggravate environmental pollution (Zhang and Dong 2021). Therefore, when the economy recovers, the public will put pressure on the government to increase environmental regulation, which, in turn, will lead to an increase in the carbon cost of control enterprises. Companies will also be more willing to innovate and adopt green technologies (Dong et al. 2021a), reducing their demand for carbon emission rights, and therefore, the macroeconomic situation is negatively correlated with carbon price. Due to the impact of the COVID-19 pandemic, the global economy is currently in a marked downturn, and all countries are in urgent need of
Fig. 2 Breakpoint of the EU carbon price structure

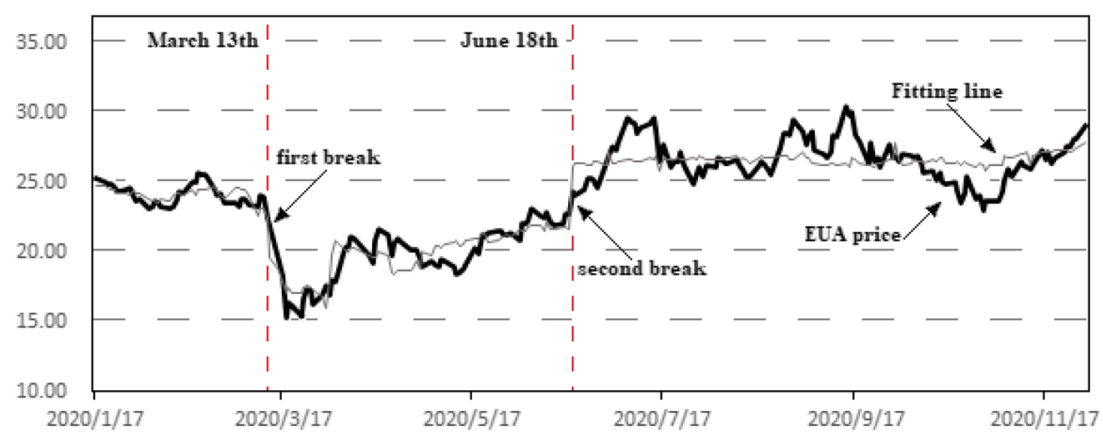


Table 7 Newey-West regression results

\begin{tabular}{|c|c|c|c|c|c|c|}
\hline Variable & Model 1 & Model 2 & Model 3 & Model 4 & Model 5 & Model 6 \\
\hline $\mathrm{RP}$ & $0.22 * * *(7.82)$ & $0.30 * * *(10.5)$ & $0.34 * * *(8.08)$ & $0.25 * *(7.38)$ & $0.25 * * *(7.41)$ & $0.19 * * *(5.90)$ \\
\hline $\mathrm{COV}$ & & $-0.20 * * *(-7.15)$ & $-0.23 * * *(-4.55)$ & $-0.14 * * *(-2.57)$ & $-0.15 * * *(-2.99)$ & $-0.15 * * *(-4.25)$ \\
\hline LnEc & & & $-0.24 *(-1.81)$ & $-0.27 * *(-2.48)$ & $-0.24 * *(-2.12)$ & $-0.20 * *(-2.35)$ \\
\hline $\mathrm{LnBr}$ & & & & $0.26 * * *(3.91)$ & $0.28 * * *(3.79)$ & $0.22 * * *(3.49)$ \\
\hline LnCer & & & & & $0.20(1.37)$ & $0.11(0.81)$ \\
\hline I & & & & & & $-5.00 * *(-3.53)$ \\
\hline Cons & $3.06 * * *(117)$ & $3.18 * * *(342)$ & $4.31 * * *(6.92)$ & $3.38 * * *(5.95)$ & $3.44 * * *(6.16)$ & 1.09 (1.39) \\
\hline $\mathrm{AR}(2)$ & 0.57 & 0.76 & 0.78 & 0.84 & 0.84 & 0.86 \\
\hline$F$ statistic & 292 & 357 & 268 & 294 & 236 & 230 \\
\hline
\end{tabular}

$t$ statistics are in parentheses

$* P<0.1 ; * * P<0.05 ; * * * P<0.01$

recovery. Governments should consider not only economic recovery, but also the public demand for a green environment. It should combine economic recovery with sustainable development and implement a green recovery policy. The COVID-19 pandemic could lead to a transition to a low-carbon economy. To verify whether the empirical results are robust, the economic prosperity index was replaced with the industrial production prosperity index to verify the robustness of the regression results.

From the results of the Newey-West regression, it can be seen that crude oil price had a positive impact on carbon price. This was because as the price of crude oil rises and the production costs of emission control increase, companies may be more inclined to use alternative energy sources, such as coal and new energy. However, due to the technological instability of new energy, it cannot be deployed on a large scale. Many companies will therefore choose coal as their preferred alternative. Coal has the highest carbon dioxide emission potential among the fossil fuels (Dong et al. 2019), and its consumption will therefore increase the demand for carbon emission rights by enterprises, causing the carbon price to rise. This indicates that the development of new energy technology is of great significance to decarbonization goals. Only through the development of new energy can the burning of traditional fossil fuels be replaced, enabling industry to achieve true decarbonization (Lin and Tan 2021).

The regression results also showed that carbon price was negatively correlated with peer dismantling rates, and the correlation was significant. This indicates that there is a transmission mechanism between the financial market and the carbon market, and fluctuations in the financial market environment will affect the carbon price. When peer lending rates increase, market liquidity becomes weaker, the financial risks of society as a whole increase, and the loanable funds of emission control companies decrease, which is not conducive to the expansion of production by enterprises. The demand for carbon allowances decreases, and carbon price also decreases. When the interest rate decreases, the liquidity of social funds increases, and the loanable funds of emission control production companies increase. These companies will increase the scale of production, energy consumption will increase, and the demand for carbon allowances will increase, which will cause the price of carbon allowances to rise. With the COVID-19 pandemic, the global economic recession, and the weak consumer market, banks will reduce interbank lending rates, expand the scale of loans, increase social investment, and reduce the cost of lending. To increase their competitiveness in the future market, enterprises should seize the opportunity to use financing funds for the development of new energy technologies, reduce the carbon intensity of unit emissions, and improve the efficiency of energy technologies.

However, from the regression results of the certified emission reduction price, although the certified emission reduction price and the carbon futures price were positively correlated, the relationship did not pass the significance test. This was inconsistent with the theory that the EU carbon futures price significantly influences the certified emission reduction price (Kamdem et al. 2016; Tang et al. 2017). There were two reasons for the lack of significance in the regression results. First, compared with the EU carbon emissions trading scheme, the carbon credit market represented by the CDM is a relatively small secondary market. Moreover, due to the postponement of the $26^{\text {th }}$ Conference of Contracting Parties, the carryover problem under the CDM project has not been effectively resolved, and the uncertainty in the CDM market has resulted in losing its influence on the EUA. Second, with the signing of the Paris Agreement, all parties have changed their original emission reduction timelines and commitments, and they all suffer pressure from their nationally determined contribution commitments. This has had a profound impact on carbon credit trading in the era of the Kyoto Protocol. To achieve overall global emission reductions and avoid 
zero-sum offset mechanisms, many countries have begun to question the feasibility of the CDM. The uncertainty of emission reductions has resulted in inactivity in the CDM market, and Cer price has remained low. Hence, the price of carbon futures and the certified emission reduction price have lost their relevance.

\section{Robustness analysis}

\section{The endogenous test}

There may have been a two-way causal relationship between the explained and explanatory variables in this study, resulting in an endogeneity problem. When the carbon futures price changes, companies will consider their own interests and choose different types of fossil energy, which will cause fluctuations in oil price. These price fluctuations will also cause companies to use certified emission reductions, which will lead to fluctuations in the certified emission reduction price (Qi and Wang 2020). To avoid this endogenous problem, in this study, there was a time lag of one period introduced, in which the price of oil and the certified emission reduction price replaced the current price as the control variable. Because the price of oil in the previous period will affect the company's choice of energy and fuel, the price of carbon cannot affect the price of oil in the previous period. Similarly, the international carbon credit market and the EU ETS were correlated. The certified emission reduction price in the previous period can affect the price of carbon futures, while the certified emission reduction price in the lag period will not be affected by the current EUA price. The NeweyWest regression coefficients are shown in Fig. 3.

After further controlling the potential endogenous problems, the carbon price was still negatively correlated with the impact of the COVID-19 pandemic and positively correlated with the recovery plan. The sign of the regression coefficient of the control variables was also the same. This verifies the robustness of the previous empirical conclusions.

\section{The robustness of the replacement control variables}

The industrial confidence index reflects the production environment of industrial enterprises and the speed of industrial development, and it is therefore an important indicator of economic prosperity. Therefore, the industrial production confidence (IPC) index was used to replace the economic prosperity index to test the robustness of the regression results. The results of each coefficient are shown in Fig. 4.

The sign of the regression results after replacing the control variable was basically the same as the original regression result. At the same time, the sign of the industrial confidence index was still negative, which may be related to the increased awareness for environmental protection of society as a whole.

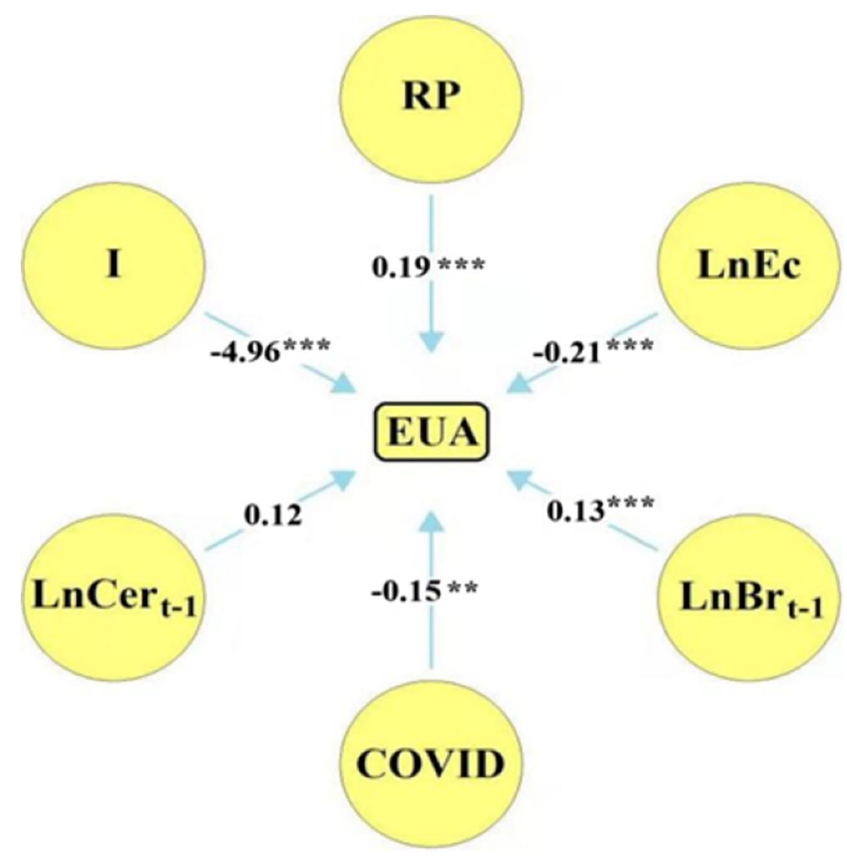

Fig. 3 Endogenous test coefficient

Although rapid economic development can drive energy consumption, with the recovery and development of the economy, industry will make considerable profits (Dong et al. 2021b). Enterprises have consciously used funds for technology research and development upgrade, thereby reducing carbon dioxide emissions and causing carbon price to fall. At the same time, under the guidance of government policies, the public is also optimistic about the future carbon market, and funds have begun to flow into green-related investment

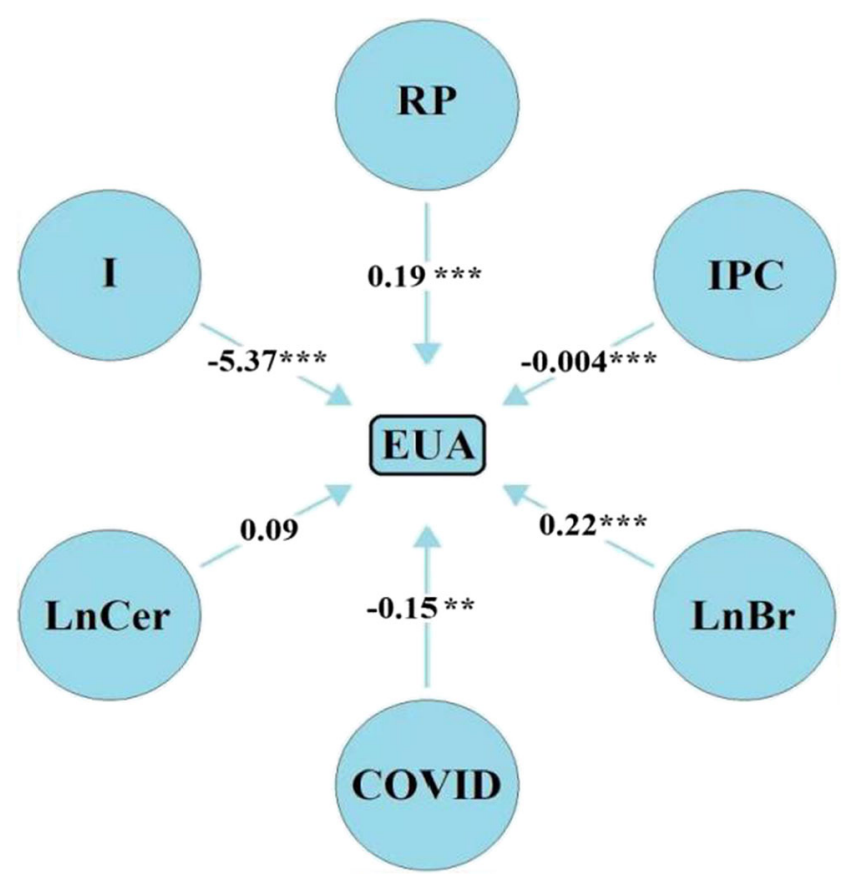

Fig. 4 The test coefficient of the replacement control variable 
projects. As a result, the overall economic environment of society has become depressed, and carbon price has risen. Hence, in the face of the COVID-19 crisis, the government can achieve economic recovery through the green recovery plan. The RP coefficient further illustrated the effectiveness of the recovery plan, thereby increasing public confidence in green recovery. Although the COVID-19 pandemic is now spreading and causing a widespread economic recession, it has made the public more aware of the importance of environmental protection. Increased awareness of environmental protection will help companies achieve decarbonization, enabling countries to achieve their climate pledges made in response to the Paris Agreement.

\section{Conclusions and policy recommendations}

\section{Research conclusions}

This study considered the EU carbon allowance futures price during the COVID-19 pandemic as the research objective and used structural breakpoint testing, the Johansen cointegration technique, and the Newey-West regression estimation to analyze the factors affecting carbon price fluctuations. The research results showed that the outbreak of the COVID-19 pandemic caused a significant drop in carbon price. However, with the introduction of the $€ 750$ billion green recovery plan, the carbon market has gradually stabilized and carbon price has begun to rise. This affirms the effectiveness of the EU's "green recovery plan" to stabilize the carbon market during the COVID-19 pandemic. The EU government should implement the green recovery plan rationally through the COVID-19 crisis to promote the realization of the Paris climate pledge.

\section{Policy recommendations}

Based on an analysis of the above regression results, the following policy recommendations are proposed.

Frist, countries in the world should rationally implement green economic recovery plans to stimulate economic growth. The COVID-19 pandemic has caused countries around the world to adopt isolation and lockdown policies. The overall global economy has stagnated. Regardless of whether the company is under the control of carbon emission rights, the company is at risk. When the government provides emergency relief to enterprises, it must seriously consider the impact of recovery stimulus measures on the environment. At the same time, enterprises with outdated production capacity should be eliminated to effectively avoid the adverse impact of stimulus measures on the environment. Policy continuity is conducive to economic recovery and will promote the realization of international climate commitments.
Second, increasing the development of clean energy technologies and reducing the use of fossil energy. The EU government should increase investment in wind energy and solar photovoltaic power generation technologies, improve the stability of renewable energy power generation, and reduce the carbon intensity of corporate power generation. Reducing society's dependence on fossil fuel energy is not only conducive to the development of the EU's future hydrogen energy strategy, but also of great significance to achieving the goal of carbon neutrality.

Third, the monitoring, reporting, and verification of carbon emissions should be strengthened. With the further advancement of the EU's green recovery plan and the forthcoming reform of the fourth phase of the EU ETS, carbon price will hopefully rise further. Although the current carbon price has gradually recovered, it has not reached the price required by the Paris Agreement climate commitments, and therefore, it is anticipated that the carbon price will rise further. With rising carbon price, the monitoring, reporting, and verification of carbon emissions are crucial.

Fourth, a regional carbon credit market should be established to increase the flexibility of emission reduction for complying entities. The emissions covered by the EU ETS account for $45 \%$ of the total emissions, but this is still a long way for achieving the goal of carbon neutrality. In the future, the EU ETS will cover more sectors and further reduce carbon emissions. Therefore, the EU should actively build a carbon credit market in its own region and increase the compliance flexibility of relevant departments through the carbon credit market. The carbon credit market could also attract sectors with non-mandatory coverage and encourage them to innovate low-carbon technologies, reduce emissions, and promote the realization of the EU's carbon neutral goal.

Author contribution Feng Dong conceived the idea of this paper. Yujin Gao, Yangfan Li, Jiao Zhu, Mengyue Hu, and Xiaoyun Zhang performed the model. Feng Dong and Yujin Gao wrote the paper.

Funding This work was supported by the Major Project of National Social Science Foundation of China (Grant No. 21ZDA86), the National Natural Science Foundation of China (Grant Nos. 71974188 and 71573254), and the Humanities and Social Sciences Special Research Fund of Ministry of Education in China (Research on Talents Training for Engineering Science and Technology, Grant No. 19JDGC011).

Data availability Data and materials are available from the authors upon request.

\section{Declarations}

Ethics approval and consent to participate Not applicable.

Consent for publication Not applicable. 
Competing interests The authors declare no competing interests.

\section{References}

Aatola P, Ollikainen M, Toppinen A (2013) Price determination in the EU ETS market: theory and econometric analysis with market fundamentals. Energy Econ 36:380-395

Adhurim H, Mario L (2021) Effects of electricity demand reductions under a carbon pricing regime on emissions: lessons from COVID-19. Energ Policy 156:112392

Alberola E, Chevallier J, Cheze B (2008) Price drivers and structural breaks in European carbon prices 2005-2007. Energ Policy 36: 787-797

Aune FR, Golombek R (2021) Are carbon prices redundant in the 2030 EU climate and energy policy package? Energy J 42

Bai J, Perron P (2003) Computation and analysis of multiple structural change models. J Appl Econ 18:1-22

Bel G, Joseph S (2015) Emission abatement: untangling the impacts of the EU ETS and the economic crisis. Energy Econ 49:531-539

Creti A, Jouvet P, Mignon V (2012) Carbon price drivers: phase I versus phase II equilibrium? Energy Econ 34:327-334

de Perthuis C, Trotignon R (2014) Governance of $\mathrm{CO}_{2}$ markets: lessons from the EU ETS. Energ Policy 75:100-106

Dong F, Li Y, Zhang X, Zhu J, Zheng L (2021a) How does industrial convergence affect the energy efficiency of manufacturing in newly industrialized countries? Fresh evidence from China. J Clean Prod $316: 128316$

Dong F, Pan Y, Li Y, Zhang S (2021b) How public and government matter in industrial pollution mitigation performance: evidence from China. J Clean Prod 306:127099

Dong F, Yu B, Pan Y (2019) Examining the synergistic effect of $\mathrm{CO}_{2}$ emissions on PM2.5 emissions reduction: evidence from China. J Clean Prod 223:759-771

Duan K, Ren X, Shi Y, Mishra T, Yan C (2021) The marginal impacts of energy prices on carbon price variations: evidence from a quantileon-quantile approach. Energy Econ 95:105131

Feng Z, Zou L, Wei Y (2011) Carbon price volatility: evidence from EU ETS. Appl Energy 88:590-598

Gerlagh R, Heijmans RJRK, Rosendahl KE (2020) COVID-19 tests the market stability reserve. Environ Resour Econ 76:855-865

Hao Z, Jin Q, Bo D (2021) Optimal pricing decisions for a low-carbon supply chain considering fairness concern under carbon quota policy. Int J Env Res Pub Health 18:556

Hua Y, Dong F, Goodman J (2021) How to leverage the role of social capital in pro-environmental behavior: a case study of residents' express waste recycling behavior in China. J Clean Prod 280: 124376

Ji C, Hu Y, Tang B (2018) Research on carbon market price mechanism and influencing factors: a literature review. Nat Hazards 92:761-782

Kamdem JS, Nsouadi A, Terraza M (2016) Time-frequency analysis of the relationship between EUA and CER carbon markets. Environ Model Assess 21:279-289

Khurshid A, Khan K (2020) How COVID-19 shock will drive the economy and climate? A data-driven approach to model and forecast. Environ Sci Pollut Res

Koch N, Grosjean G, Fuss S, Edenhofer O (2016) Politics matters: regulatory events as catalysts for price formation under cap-and-trade. J Environ Econ Manag 78:121-139
Li Y, Liu T, Song Y, Li Z, Guo X (2021) Could carbon emission control firms achieve an effective financing in the carbon market?A case study of China's emission trading scheme. J Clean Prod 314:128004

Lin B, Tan Z (2021) How much impact will low oil price and carbon trading mechanism have on the value of carbon capture utilization and storage (CCUS) project? Analysis based on real option method. J Clean Prod 298:126768

Liu Y, Dong F (2021) Haze pollution and corruption: a perspective of mediating and moderating roles. J Clean Prod 279:123550

Liu H, Kou X, Xu G, Qiu X, Liu H (2021) Which emission reduction mode is the best under the carbon cap-and-trade mechanism? J Clean Prod 314:128053

Martin H (2020) A carbon price floor in the reformed EU ETS: design matters! Energ Policy 147:111905

Mansanet-Bataller M, Chevallier J, Herve-Mignucci M, Alberola E (2011) EUA and sCER phase II price drivers: unveiling the reasons for the existence of the EUA-sCER spread. Energ Policy 39:10561069

Mansanet-Bataller M, Pardo A, Valor E (2007) $\mathrm{CO}_{2}$ prices, energy and weather. Energy J 28:73-92

Markus F, Markus B, Marco B, Gregor H, Murphy MD (2021) The effect of price-based demand response on carbon emissions in European electricity markets: the importance of adequate carbon prices. Appl Energy 295:117040

Newey WK, West KD (1994) Automatic lag selection in covariance matrix estimation. Rev Econ Stud 61(4):631-653

Qi S, Wang W (2020) The impact of the phase III reform of European Union Emissions Trading System on carbon allowance price. J Environ Econ 5:1-20 (in Chinese)

Pan Y, Dong F (2021) How to optimize provincial PM2.5 reduction targets and paths for emerging industrialized countries? Fresh evidence from China. Environ Sci Pollut Res Available online

Richstein JC, Chappin EJL, de Vries LJ (2015) The market (in-)stability reserve for EU carbon emission trading: why it might fail and how to improve it. Util Policy 35:1-18

Rittler D (2012) Price discovery and volatility spillovers in the European Union emissions trading scheme: a high-frequency analysis. J Bank Financ 36:774-785

Tang B, Gong P, Shen C (2017) Factors of carbon price volatility in a comparative analysis of the EUA and sCER. Ann Oper Res 255: $157-168$

Zhang X, Dong F (2021) How virtual social capital affects behavioral intention of sustainable clothing consumption pattern in developing economies? A case study of China. Resour Conserv Recycl 170: 105616

Zhao L, Mao J, Qu S, Chen X (2021) A multi-factor integrated model for carbon price forecasting: market interaction promoting carbon emission reduction. Sci Total Environ 796:149110

Zhou J, Chen D (2021) Carbon price forecasting based on improved CEEMDAN and extreme learning machine optimized by Sparrow search algorithm. Sustainability-Basel 13:8413

Zhu B, Ye S, Han D, Wang P, He K, Wei Y, Xie R (2019) A multiscale analysis for carbon price drivers. Energy Econ 78:202-221

Publisher's note Springer Nature remains neutral with regard to jurisdictional claims in published maps and institutional affiliations. 